\title{
Resource and cost considerations in treating hypoplastic left heart syndrome
}

This article was published in the following Dove Press journal:

Pediatric Health, Medicine and Therapeutics

16 November 2016

Number of times this article has been viewed

\author{
Miguel Urencio' \\ Chris Greenleaf' \\ Jorge D Salazar ${ }^{2}$ \\ Ali Dodge-Khatami \\ 'Division of Cardiothoracic Surgery, \\ ${ }^{2}$ Children's Heart Center, University \\ of Mississippi Medical Center, Jackson, \\ MS, USA
}

\begin{abstract}
Hypoplastic left heart syndrome (HLHS) was a uniformly fatal diagnosis before 1983, when surgical treatment was first undertaken with the Norwood I operation as the first of 3-staged operations. Since then, operative survival rate of stage I has risen from $53 \%$ to over $90 \%$ in the current era, not only thanks to technical advances in surgery but also through prenatal diagnosis and imaging, enhanced cardiopulmonary bypass technology, better perioperative intensive care, and closer interstage monitoring. The improvements in patient outcomes achieved through rigorous multidisciplinary teamwork have come at a tremendous cost in manpower and resources, making HLHS still a challenge to all congenital heart programs, established or emerging. We review the various surgical steps to treat HLHS and their current expected outcomes, and put into perspective cost considerations compared to other more "simple" congenital heart defects. Keywords: hypoplastic left heart syndrome, Norwood, congenital heart disease
\end{abstract}

\section{Hypoplastic left heart syndrome}

Hypoplastic left heart syndrome (HLHS) represents between 2 and $3 \%$ of all congenital heart malformations. It is present in 1 out of 4,344 live births in the US with an incidence around 1,000 patients a year. ${ }^{1}$ This syndrome is a spectrum of congenital malformations characterized by the underdevelopment of the left ventricle (LV) and left outflow tract including hypoplasia of the LV, atresia, stenosis or hypoplasia of the aortic and/or mitral valves, and hypoplasia of the ascending aorta and aortic arch. The systemic circulation is ductal-dependent (needs a patent ductus arteriosus [PDA] for survival) and requires an atrial septal defect for adequate mixing. This condition is uniformly fatal if not treated and is the most common cause of cardiac death in patients $<1$ month old. ${ }^{2}$ No known causes have been found for this condition, but some genetic component is suspected, as well as hereditary and environmental causes. ${ }^{3,4}$ It is usually an isolated cardiac defect, but some genetic syndromes are occasionally associated. ${ }^{5}$ The risk of recurrence in future pregnancies is estimated at $2-4 \%$, but this can increase to $25 \%$ in families with 2 affected children. Outcomes have improved with earlier diagnosis, and currently, 2 out of 3 infants with this condition are diagnosed prenatally. ${ }^{6-9}$

These patients appear healthy at birth, but as the PDA starts to close and pulmonary vascular resistance decreases, they develop pulmonary over-circulation with pulmonary edema and inadequate systemic perfusion, which eventually cause acidosis and shock. This manifests with tachycardia, tachypnea, and hypoxia. The chest X-ray will show evidence of pulmonary venous congestion, a prominent right ventricle border, and a cardiac silhouette which may appear hypoplastic, normal, or enlarged. The initial
Children's Heart Center, University of Mississippi Medical Center, 2500 North State Street, Room S345, Jackson, MS

39216, USA

$\mathrm{Tel}+\mathrm{I} 6019845489$

$\mathrm{Fax}+\mathrm{I} 6019845872$

Email adodgekhatami@umc.edu 
treatment is medical, consisting of intravenous prostaglandins to assure ductal patency, as well as deliberate room air spontaneous respiration to keep oxygen saturations between 75 and $85 \%$, and hypoventilation to keep a higher $p \mathrm{CO}_{2}$ (40-50 $\mathrm{mmHg}$ ) to increase pulmonary vascular resistance, thereby improving systemic blood flow. Keeping preoperative oxygen saturations between 75 and $85 \%$ corresponds to a balanced systemic-to-pulmonary circulation, according to the Fick equation. Ideally, spontaneous respiration on room air should be sufficient to keep a balanced circulation. However, if necessary, elective intubation and hyperbaric ventilation may be provided to control excessive pulmonary blood flow, and in rare extreme situations, addition of nitrogen to the oxygen content is required to achieve this goal. After stabilization of the neonate for a few days, surgical palliation is undertaken in the first week of life.

The most common pathway to treat HLHS includes 3 -staged operations with the Norwood stage I procedure ${ }^{10}$ in the first week of life, a partial cavo-pulmonary anastomosis (bidirectional Glenn or Hemi-Fontan) at 3-8 months of age, and a total cavo-pulmonary anastomosis (Fontan procedure) when the patient is about 2-4 years old. The Norwood procedure is a very complex operation that requires cardiopulmonary bypass (CPB), moderate-to-deep hypothermia, and a challenging reconstruction of the ascending aorta and aortic arch, plus a source of pulmonary blood flow, being either 1) a systemic-to-pulmonary artery (PA) shunt or 2) a right ventricular-PA conduit. According to the latest findings of the largest multicenter study conducted by the Congenital Heart Surgeons' Society (CHSS), neonates who undergo Norwood stage I palliation with the right ventricular-PA conduit have superior 6-year overall survival and transplant-free survival, compared with those who undergo palliation with a systemicto-PA shunt (Figure 1). ${ }^{11}$

In the last decades, an alternative strategy to the Norwood stage I, called the "hybrid approach", has shown promising results. $^{12-14}$ This consists of placing bilateral PA bands and

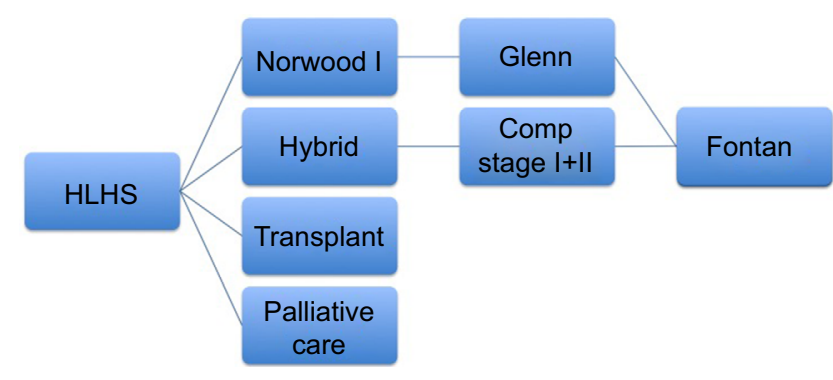

Figure I Treatment algorithm for HLHS.

Abbreviations: HLHS, hypoplastic left heart syndrome; Comp, comprehensive. a stent in the PDA, ${ }^{15}$ also during the first week of life. This approach has the advantage of avoiding the potential risks of CPB, cardioplegic cardiac arrest, and hypothermia in the neonatal period but shifts the complexity to the second operation at a later stage. In patients with a restrictive inter-atrial septum, a balloon atrial septostomy, with or without atrial stenting, is often required prior to home discharge.

If the hybrid approach is done during the neonatal period, a comprehensive stage I+II procedure is done at 3-6 months of life. This procedure involves complex surgery where the PDA stent and PA artery bands are removed, the PAs and aortic arch are reconstructed, and a bidirectional Glenn or Hemi-Fontan procedure is performed. Timing of the final stage III completion Fontan operation remains at around 2-4 years of age, similar to that after a Norwood I followed by a bidirectional Glenn (or Hemi-Fontan) procedure.

Heart transplantation has always been, in theory, a very attractive option. However, the ever-present risk of rejection and infection in children due to lifelong immunosupression has to be taken into account. The very small number of suitable donor hearts is one of the most limiting factors for this approach, so most centers have abandoned cardiac transplantation as the primary mode to treat HLHS. ${ }^{16}$ There are about 100 infant heart transplants in the US per year for all cardiac diagnoses. ${ }^{17}$ Transplantation has become a secondary or salvage therapy for patients who have failed the staged reconstruction or those who have failed Fontan physiology. ${ }^{18-21}$

Survival rates of stage I palliation have significantly improved in the last 3 decades since the introduction of the Norwood procedure from $56 \%$ in 1983 to $90 \%$ in 2014 for low-risk anatomic variants. ${ }^{22}$ For high-risk HLHS variants, which include anatomical subtypes of aortic atresia/mitral atresia+aortic atresia/mitral stenosis, intact or restrictive atrial septum, poor ventricular function, tricuspid regurgitation, and micro-ascending aorta (less than $2 \mathrm{~mm}$ ), mortality ranges from 20 to $50 \% .{ }^{23}$ Other noncardiac risk factors are shock at presentation, birth weight less than $2.5 \mathrm{~kg}$, gestational age less than 34 weeks, or serious noncardiac genetic malformations. ${ }^{23}$

In the interstage Norwood to Glenn (or Hemi-Fontan) period, which is a time theoretically spent at home by the infant while waiting for stage II palliation, mortality ranges from 4 to $16 \%{ }^{24}$ Survival rate of the Glenn (or Hemi-Fontan) operation is excellent, ranging between 95 and 100\%. The interstage mortality from Glenn (or Hemi-Fontan) to Fontan (stages II-III, which is also time spent at home), is around $9 \%{ }^{25}$ Contemporary survival rates of the Fontan operation have also considerably improved, comparable to the stage II Glenn (or Hemi-Fontan) operation at 95-100\%. In the 
largest multi-institutional cohort studied by the CHSS to date, overall survival rate of neonates after any type of Norwood I palliation is $62 \pm 3 \%$ at 6 years. ${ }^{11}$

Improved outcomes for this otherwise lethal disease require a multidisciplinary team of congenital heart surgeons, cardiologists, pediatric intensivists, cardiac anesthesiologists, specialized nursing staff, perfusionists, and social workers, just to name a few. Cost implications are considerable, and hospitals need to be equipped with the infrastructure to support the staff. The operating rooms need to be adequate to accommodate the CBP machine, cardiac anesthesia, and transesophageal echocardiogram. A catheterization lab and an in-house extracorporeal membrane oxygenation (ECMO) program are necessary as well as imaging with computed tomography scan and magnetic resonance imaging, transport teams, and neonatal and fetal center capabilities. ${ }^{26}$ The catheterization lab with biplane fluoroscopy is a cornerstone if a center wants to perform the hybrid stage I palliation, as well as planned diagnostic catheterization before stage II and III, to obtain full imaging and physiological data in order to plan the upcoming respective surgical palliations.

The current expectations of patients who survive to the age of 1 year are a long-term survival of $90 \%$, with $70 \%$ of them reaching adulthood. ${ }^{5}$ These improved outcomes are associated with higher case volumes of each institution, where centers with a larger volume have better outcomes. ${ }^{27}$ The length of stay (LOS) for a patient after a Norwood procedure is around 28 days with a cost close to $\$ 110,000$ (US), and hospital charges around $\$ 280,000$, making the daily hospital cost for these patients around $\$ 7,000$ to $\$ 10,000$. The LOS, cost, and charges are similar between patients who undergo the Glenn (or Hemi-Fontan) and Fontan procedures, with an LOS of 9-11 days, costs of $\$ 40,000$, and charges close to $\$ 100,000$, which are approximately one-third of the total amount for those who undergo a Norwood stage I palliation. ${ }^{28}$ Of the treatment options for HLHS, cardiac transplantation, either as primary or as rescue therapy, is associated with the highest use of resources. The LOS is around 87 days with costs of almost $\$ 3,000,000$ and charges of $\$ 580,000$, making cardiac transplantation the most expensive option. ${ }^{29-31}$

In comparison to HLHS, a high-risk operative category, less complex cardiac diagnosis such as atrial and ventricular septal defects or tetralogy of Fallot ${ }^{32}$ is associated with lower risk surgery, less likelihood of complications, and shortened intensive care unit and hospital stays. ${ }^{33}$ The median cost of cardiac surgery for all children is around \$51,000, making HLHS treatment almost twice as costly as the average cardiac operation. ECMO support, which can occasionally be needed after a Norwood I operation, and almost never so after more common repairs of low-risk diagnoses, is also associated with increased resource utilization. ${ }^{34}$

These costs are only for the surgeries, but it is important to remember that patients with HLHS face outpatient clinic visits, imaging studies, cardiac catheterizations, myocardial biopsies (for transplanted patients), and medications for their entire life. The financial burden for families, hospitals, insurance companies, and government agencies is most likely to be increased in the future, since the success of surgical palliation has been improved and mortality has been decreased in the last 30 years. Before 1990, these patients had limited healthcare costs because the only available option was comfort care and they died shortly after birth.

The improved overall survival of patients with HLHS is not only due to surgical and in-hospital innovations by all professionals taking care of these patients but also thanks to enhanced interstage follow-up and closer monitoring between operations. Home monitoring strategies have been implemented to detect vital sign variations that parents can measure, which would precede significant deterioration of the baby's health status. The program consists of daily oxygen saturation level monitoring and daily weight measurement by parents or guardians, who will have been trained prior to hospital discharge. Follow-up by telephone calls by members of the congenital heart care-giving group is done on a weekly basis, as well as by having an on-call person available 24 hours a day, 7 days a week. The home monitoring program is an inexpensive measure that has reduced the interstage mortality between the Norwood and Glenn (or Hemi-Fontan) operations, with a survival rate of $98 \% .{ }^{35}$ It costs around $\$ 800$ a month for the patient's family to get a pulse oxymeter and an infant scale which are usually covered by private insurance and Medicaid, in the US. Besides being cheap, they have helped to prevent interstage deaths, by recognizing inadequate growth or inappropriate oxygen saturations commonly seen in infants with shunt-dependent physiology. Complementing the interstage home monitoring programs, specialized interstage outpatient clinics with dedicated cardiac physicians, nurse practitioners, dieticians, and staff have tremendously enhanced the quality of care and optimization of patients for future stages.

In conclusion, embarking upon a program for treating babies with HLHS involves more than just a surgical team with skills to operate. It requires huge manpower at all physician and nursing levels, resources, equipment, infrastructure, and political/economical administrative support, which go well beyond the mere neonatal period of any 
given patient. As mentioned, enhanced survival and current improving results are prolonging the life span of these patients into adulthood, making any center's commitment to treat them a generational one. The best outcomes come from high-volume centers, ${ }^{27}$ so any new program starting with smaller patient numbers will require a meticulous inquiry and self-evaluation to plan and ensure sustainable quality of outcomes. If the results are not those expected, as defined by benchmark reports, system deficiencies should be sought out to attempt improving patient outcomes. Most financial reports will attest that Norwood I palliation and cardiac transplantation are the most expensive treatment arms. It has been suggested that the hybrid stage I is less costly, and can give more time to patients' families in developing countries to arrange financial and medical support for the ulterior comprehensive stage I+II surgery. ${ }^{36}$ Meticulous planning should be considered by all centers wanting to start programs to treat HLHS, which remains the most challenging of cardiac diagnoses to obtain consistent excellent outcomes in a sustainable fashion.

\section{Disclosure}

The authors report no conflicts of interest in this work.

\section{References}

1. Rychik J, Wernovsky G, editors. Hypoplastic Left Heart Syndrome. Boston, MA: Kluwer Academic Publishers; 2003.

2. Wernovsky G. The paradigm shift toward surgical intervention for neonates with hypoplastic left heart syndrome. Arch Pediatr Adolesc Med. 2008;162(9):849-854.

3. Schidlow DN, Tworetzky W, Wilkins-Haug LE. Percutaneous fetal cardiac interventions for structural heart disease. Am J Perinatol. 2014;31(7):629-636.

4. Eghtesady P, Brar A, Hall M. Seasonality of hypoplastic left heart syndrome in the United States: a 10-year time-series analysis. J Thorac Cardiovasc Surg. 2011;141(2):432-438.

5. Feinstein JA, Benson DW, Dubin AM, et al. Hypoplastic left heart syndrome: current considerations and expectations. J Am Coll Cardiol. 2012;59(1 Suppl):S1-S42.

6. Atz AM, Travison TG, Williams IA, et al. Prenatal diagnosis and risk factors for preoperative death in neonates with single right ventricle and systemic outflow obstruction: screening data from the Pediatric Heart Network Single Ventricle Reconstruction Trial (*). JThorac Cardiovasc Surg. 2010;140(6):1245-1250.

7. Israel SW, Roofe LR, Saville BR, Walsh WF. Improvement in ante-natal diagnosis of critical congenital heart disease implications for postnatal care and screening. Fetal Diagn Ther. 2011;30(3):180-183.

8. Khoo NS, Van Essen P, Richardson M, Robertson T. Effectiveness of prenatal diagnosis of congenital heart defects in South Australia: a population analysis 1999-2003. Aust N Z J Obstet Gynaecol. 2008;48(6):559-563.

9. Rasiah SV, Ewer AK, Miller P, et al. Antenatal perspective of hypoplastic left heart syndrome: 5 years on. Arch Dis Child Fetal Neonatal Ed. 2008;93(3):F192-F197.

10. Norwood WI, Lang P, Hansen DD. Physiologic repair of aortic atresia-hypoplastic left heart syndrome. N Engl J Med. 1983;308(1): $23-26$.
11. Wilder TJ, McCrindle BW, Phillips AB, et al. Survival and right ventricular performance for matched children after stage-1 Norwood: modified Blalock-Taussig shunt versus right-ventricle-to-pulmonary-artery conduit. J Thorac Cardiovasc Surg. 2015;150(6):1440-1450, 1452.

12. Honjo $\mathrm{O}$, Caldarone $\mathrm{CA}$. Hybrid palliation for neonates with hypoplastic left heart syndrome: current strategies and outcomes. Korean Circ J. 2010;40(3):103-111.

13. Pizarro C, Derby CD, Baffa JM, Murdison KA, Radtke WA. Improving the outcome of high-risk neonates with hypoplastic left heart syndrome: hybrid procedure or conventional surgical palliation? Eur J Cardiothorac Surg. 2008;33(4):613-618.

14. Galantowicz M, Yates AR. Improved outcomes with the comprehensive stage 2 procedure after an initial hybrid stage 1. J Thorac Cardiovasc Surg. 2016;151(2):424-429.

15. Gibbs JL, Wren C, Watterson KG, Hunter S, Hamilton JR. Stenting of the arterial duct combined with banding of the pulmonary arteries and atrial septectomy or septostomy: a new approach to palliation for the hypoplastic left heart syndrome. Br Heart J. 1993;69(6):551-555.

16. Bailey LL, Nehlsen-Cannarella SL, Doroshow RW, et al. Cardiac allotransplantation in newborns as therapy for hypoplastic left heart syndrome. N Engl J Med. 1986;315(15):949-951.

17. Chinnock RE, Bailey LL. Heart transplantation for congenital heart disease in the first year of life. Curr Cardiol Rev. 2011;7(2):72-84.

18. Lamour JM, Kanter KR, Naftel DC, et al. The effect of age, diagnosis, and previous surgery in children and adults undergoing heart transplantation for congenital heart disease. J Am Coll Cardiol. 2009;54:160-165.

19. del Nido P, Bailey LL, Kirklin JK. Surgical techniques in pediatric heart transplantation. In: Canter CE, Kirklin JK, editors. ISHLT Monograph Series 2, Pediatric Heart Transplantation. Philadelphia, PA: Elsevier; 2007:83-102.

20. Bailey LL. Heart transplantation techniques in complex congenital heart disease. J Heart Lung Transplant. 1993;12(6 Pt 2):S168-S175.

21. Bernstein D, Naftel D, Chin C, et al. Outcome of listing for cardiac transplantation for failed Fontan: a multi-institutional study. Circulation. 2006;114(4):273-280.

22. Stasik CN, Gelehrter S, Goldberg CS, Bove EL, Devaney EJ, Ohye RG. Current outcomes and risk factors for the Norwood procedure. JThorac Cardiovasc Surg. 2006;131:412-417.

23. Bacha EA, Daves S, Hardin J, et al. Single-ventricle palliation for highrisk neonates: the emergence of an alternative hybrid stage I strategy. J Thorac Cardiovasc Surg. 2006;131(1):163-171.e2.

24. Menson SC, Keenan HT, Weng HY, et al. Outcome and resource utilization of infants born with hypoplastic left heart syndrome in the Intermountain West. Am J Cardiol. 2012;110(5):720-727.

25. McGuirk SP, Griselli M, Stumper OF, et al. Staged surgical management of hypoplastic left heart syndrome: a single institution 12 year experience. Heart. 2006;92(3):364-370.

26. Dodge-Khatami A, Chancellor WZ, Gupta B, et al. Achieving benchmark results for neonatal palliation of hypoplastic left heart syndrome and related anomalies in an emerging program. World J Pediatr Congenit Heart Surg. 2015;6(3):393-400.

27. Checchia PA, McCollegan J, Daher N, Kolovos N, Levy F, Markovitz B. The effect of surgical case volume on outcome after the Norwood procedure. J Thorac Cardiovasc Surg. 2005;129(4):754-759.

28. Dean PN, Hillman DG, McHugh KE, Gutgesell HP. Inpatient costs and charges for surgical treatment of hypoplastic left heart syndrome. Pediatrics. 2011;128(5):e1181-e1186.

29. Mahle WT, Forbess JM, Kirshbom PM, Cuadrado AR, Simsic JM, Kanter KR. Cost-utility analysis of salvage cardiac extracorporeal membrane oxygenation in children. $J$ Thorac Cardiovasc Surg. 2005;129(5):1084-1090.

30. Mahle WT, Ianucci G, Vincent RN, Kanter KR. Costs associated with ventricular assist device use in children. Ann Thorac Surg. 2008;86(5):1592-1597.

31. Morales DL, Zafar F, Rossano JW, et al. Use of ventricular assist devices in children across the United States: analysis of 7.5 million pediatric hospitalizations. Ann Thorac Surg. 2010;90(4):1313-1318. 
32. O'Brien SM, Clarke DR, Jacobs JP, et al. An empirically based tool for analyzing mortality associated with congenital heart surgery. J Thorac Cardiovasc Surg. 2009;138(5):1139-1153.

33. Pasquali SK, Jacobs JP, Bove EL, et al. Quality-cost relationship in congenital heart surgery. Ann Thorac Surg. 2015;100(4):1416-1421.

34. Faraoni D, Nasr VG, DiNardo JA. Overall hospital cost estimates in children with congenital heart disease: analysis of the 2012 kid's inpatient database. Pediatr Cardiol. 2016;37(1):37-43.
35. Rudd NA, Frommelt MA, Tweddell JS, et al. Improving interstage survival after Norwood operation: outcomes from 10 years of home monitoring. J Thorac Cardiovasc Surg. 2014;148(4): 1540-1547.

36. Anuradha S, Subramanyan R, Agarwal R, Pezzella AT, Cherian KM. Hybrid stage I palliation for hypo-plastic left heart condition without a hybrid suite: suggestions for developing nations. Indian Heart $J$ 2012;64(4):333-337.
Pediatric Health, Medicine and Therapeutics

\section{Publish your work in this journal}

Pediatric Health, Medicine and Therapeutics is an international, peerreviewed, open access journal publishing original research, reports, editorials, reviews and commentaries. All aspects of health maintenance, preventative measures and disease treatment interventions are addressed within the journal. Practitioners from all disciplines are invited to submit

\section{Dovepress}

their work as well as healthcare researchers and patient support groups. The manuscript management system is completely online and includes a very quick and fair peer-review system. Visit http://www.dovepress.com/ testimonials.php to read real quotes from published authors.

Submit your manuscript here: http://www.dovepress.com/pediatric-health-medicine-and-therapeutics-journal 